\title{
Region-Specific Changes in the Subcellular Distribution of AMPA Receptor GluR1 Subunit in the Rat Ventral Tegmental Area after Acute or Chronic Morphine Administration
}

\author{
Diane A. Lane, ${ }^{1}$ Andree A. Lessard, ${ }^{1}$ June Chan, ${ }^{1}$ Eric E. O. Colago, ${ }^{1}$ Yan Zhou, ${ }^{2}$ Stefan D. Schlussman, ${ }^{2}$ \\ Mary Jeanne Kreek, ${ }^{2}$ and Virginia M. Pickel ${ }^{1}$ \\ ${ }^{1}$ Department of Neurology and Neuroscience, Division of Neurobiology, Weill Medical College of Cornell University, New York, New York 10021, and \\ ${ }^{2}$ Laboratory of the Biology of Addictive Diseases, The Rockefeller University, New York, New York 10065
}

\begin{abstract}
Opiate addiction is characterized by progressive increases in drug intake over time suggesting maladaptive changes in motivational and reward systems. These behaviors are mediated by dopaminergic neurons originating from the ventral tegmental area (VTA), and longterm changes of these dopaminergic neurons are attributed to increased postsynaptic glutamatergic activation. Indeed, chronic morphine administration is known to increase AMPA receptor glutamate receptor 1 (GluR1) subunit in the VTA. However, there is no ultrastructural evidence that morphine affects the expression or surface availability of GluR1 subunits in VTA neurons of defined distribution or transmitter phenotype. Therefore, we examined electron microscopic immunolabeling of GluR1 and tyrosine hydroxylase (TH) in two VTA regions of rats perfused $1 \mathrm{~h}$ after a single injection of morphine, or chronic morphine in intermittent-escalating doses for $14 \mathrm{~d}$, and appropriate saline controls. Acute morphine administration produced a significant increase in GluR1 immunogold particles at the plasma membrane and postsynaptic densities in both TH- and non-TH-containing dendrites in the parabrachial VTA, a region that contains mainly prefrontal-cortical-projecting dopaminergic neurons involved in motivation and drug-seeking behavior. Chronic morphine administration maintained the increased synaptic GluR1 labeling in the parabrachial VTA, but also increased the number of GluR1-labeled synapses and TH immunoreactivity in dendrites of the paranigral VTA where substantially more dopaminergic neurons project to limbic structures implicated in locomotor activation and reward. These results demonstrate a region- and dose-dependent redistribution of GluR1-containing AMPA receptors, which is consistent with acute morphine activation of cortical-projecting VTA neurons and chronic morphine activation of limbic-projecting VTA neurons.
\end{abstract}

Key words: synaptic plasticity; dopamine; tyrosine hydroxylase; ultrastructure; multivesicular bodies; reward

\section{Introduction}

Dopaminergic neurons in the ventral tegmental area (VTA) play a critical role in motivated goal-seeking behavior and reward (Koob and Bloom, 1988; Le Moal and Simon, 1991). Opiates indirectly activate these cells via disinhibition of GABA interneurons (Johnson and North 1992), the major cell type expressing $\mu$-opioid receptors in the VTA (Garzón and Pickel, 2001; Svingos et al., 2001). Opiates also increase AMPA receptor-mediated glutamatergic transmission to VTA dopaminergic neurons (Saal et al., 2003), via glutamatergic inputs from the medial prefrontal cortex (mPFC), lateral amygdala, and other brain regions (Carr and Sesack, 2000; Sesack et al., 2003; Geisler and Zham, 2005). This change in glutamate can, in turn, modulate dopamine release in the $\mathrm{mPFC}$ and nucleus accumbens (NAc), the respective

\footnotetext{
Received May 12, 2008; revised Aug. 13, 2008; accepted Aug. 15, 2008.

This work was supported by National Institutes of Health-National Institute on Drug Abuse Grants P60 05130 (M.J.K., V.M.P.), R01 004600 (V.M.P.), K05 00049 (M.J.K.), and T32 007274 (Charles E. Inturrisi).

Correspondence should be addressed to Dr. Diane A. Lane, Department of Neurology and Neuroscience, Division of Neurobiology, Weill Medical College of Cornell University, 411 East 69th Street, Room 410, New York, NY 10021. E-mail: dal2021@med.cornell.edu.

DOl:10.1523/JNEUROSCI.2151-08.2008

Copyright $\odot 2008$ Society for Neuroscience $\quad$ 0270-6474/08/289670-12\$15.00/0
}

primary targets of parabrachial (PB) and paranigral (PN) VTA projection neurons (Kalivas et al., 1989; Taber and Fibiger, 1995; Karreman and Moghaddam, 1996; Meltzer et al., 1997; Kretschmer, 1999).

Lasting changes in AMPA receptor-mediated glutamatergic transmission in VTA dopaminergic neurons are thought to contribute to the development of addiction (Wolf, 2003). Stimuli that induce long-term potentiation (LTP) increase the number of functional AMPA receptors at synapses (Liao et al., 1995; Malinow and Malenka, 2002) and LTP can be elicited from neurons within the VTA (Bonci and Malenka, 1999). Opiates may initiate changes in VTA glutamate transmission leading to the development of addiction. In fact, a single injection of morphine enhances AMPA receptor-mediated synaptic strength in the VTA (Saal et al., 2003) and overexpression of the AMPA glutamate receptor 1 (GluR1) subunit in the VTA is sufficient to produce behavioral sensitization (Carlezon et al., 1997), an animal model of addiction thought to parallel neuroadaptations that underlie the development of addiction in humans.

There are distinct regional differences in glutamate connectivity and dopaminergic output of the VTA. The PB VTA contains predominantly cortical-projecting dopaminergic neurons that 
receive direct glutamatergic input from the $\mathrm{mPFC}$. In contrast, glutamatergic efferents target mainly GABAergic interneurons in the PN VTA (Carr and Sesack, 2000; Sesack et al., 2003; Geisler and Zahm, 2005). Thus, limbic-projecting dopaminergic neurons of the PN VTA are indirectly affected by glutamate. These differences in anatomical connectivity have opposing effects on tonic dopamine release in the mPFC and NAc (Takahata and Moghaddam, 2000). Consequently, morphine administration may produce region-specific changes in the availability and functional assembly of GluR1 subunits at the synapse. Furthermore, these mechanisms may be different depending on the duration of morphine administration.

To address these important issues, we examined the electron microscopic immunogold-labeling of the AMPA receptor GluR1 subunit in rat VTA perfused $1 \mathrm{~h}$ after acute (single injection) or chronic (14 d of intermittent escalating-dose) morphine administration. Dopaminergic neurons were identified by peroxidase labeling of tyrosine hydroxylase (TH), an essential enzyme for dopamine synthesis not present in other VTA neurons. The results show that morphine produces region-specific relocation of AMPA GluR1 subunits consistent with immediate but persistent effects on PFC-projecting mesocortical dopaminergic neurons located predominantly in the PB VTA, and more delayed effects on NAc-projecting mesolimbic dopaminergic neurons located primarily in the PN VTA.

\section{Materials and Methods \\ Animal models}

Experimental protocols involving animals and their care were approved by the Institutional Animal Care and Use Committee at Weill Medical College of Cornell University and the Rockefeller University. Male Sprague Dawley rats (Taconic Farms) of starting weight 250-300 g were individually housed and maintained on a reverse $12 \mathrm{~h}$ light cycle (lights out at 7:00 A.M.). Food and water were available ad libitum. Rats were used for either (1) retrograde identification of VTA projection neurons, or (2) systemic administration of morphine or saline.

Retrograde transport. To assure the proper selection of VTA subregions, which contain neurons projecting to the mPFC (PB-VTA) and NAc (PN-VTA) (Carr and Sesack, 2000), the location of these projection neurons was examined in two male Sprague Dawley rats with successful stereotaxic injections of the retrograde tracer Fluorogold (FG; Fluorochrome) in either the mPFC or NAc. FG is a well established tract tracing method which retrogradely labeled dendrites up to the fourth or fifth branching orders and provides labeling comparable with wheat germ agglutinin-conjugated horseradish peroxidase (Schmued and Fallon, 1986; Pieribone and Aston-Jones, 1988; Van Bockstaele et al., 1994). Iontophoretic application of FG results in selective labeling of neurons, with minimal labeling of fibers of passage (Pieribone and Aston-Jones, 1988). Each rat was anesthetized by an intraperitoneal injection of 65 $\mathrm{mg} / \mathrm{kg}$ sodium pentobarbital (Sigma) together with $0.5 \mathrm{ml}$ of a longacting local anesthetic (marcaine, 0.5\%; Abbott Laboratories). Once anesthetized, the scalp was shaved and the animal was mounted in a stereotaxic frame with the incisor bar set at $3.3 \mathrm{~mm}$ below the interaural line. The scalp was cleaned with $70 \%$ isopropyl alcohol (Cardinal Health), and betadine solution (Perdue Products) and an incision was made to expose the skull. A unilateral hole was drilled either above the $\mathrm{mPFC}$ [3.3 $\mathrm{mm}$ anteroposterior (AP); $1.0 \mathrm{~mm}$ mediolateral (ML); 2.0$4.0 \mathrm{~mm}$ dorsoventral (DV) to bregma] or the NAc (1.7 mm AP; $1.5 \mathrm{~mm}$ ML; $6.5 \mathrm{~mm}$ DV to bregma) using coordinates from the Paxinos and Watson (1986) rat brain atlas. Unilateral iontophoretic injection of FG ( $1 \% \mathrm{FG}$ in $0.1 \mathrm{M}$ sodium acetate buffer) was achieved by a $10-50 \mu \mathrm{A}$ current pulse for $5 \mathrm{~s}$ on, $5 \mathrm{~s}$ off, for a total of two $10 \mathrm{~min}$ injections into the $\mathrm{mPFC}$ (one at $4.0 \mathrm{~mm}$ and the other at $2.0 \mathrm{~mm}$ ventral to the brain surface) or $20 \mathrm{~min}$ into the NAc. The micropipette was then removed, the hole filled with bone wax, and the incision was sutured closed (Ethicon). After surgery, rats received topical application of lidocaine ointment (5\%; Fougera) and Neomycin and Polymyxin B sulfates antibiotic oint- ment (Bausch and Lomb) at the incision site. Recovery from anesthesia was closely monitored under a warm pad to maintain body temperature. After rats regained consciousness, they were housed individually in polyethylene cages and returned to animal housing. Animals were killed $7 \mathrm{~d}$ after FG injection (see below, Tissue preparation).

Acute and chronic morphine or saline administration. Twelve naive rats were randomly assigned to one of four treatment groups: acute saline, acute morphine, chronic saline, or chronic intermittent escalating morphine administration. Acute groups received one injection of either saline or morphine $(20 \mathrm{mg} / \mathrm{kg}$, i.p.) and were killed $1 \mathrm{~h}$ later. Chronic groups received three injections per day (at 10:00 A.M., 4:00 P.M., and 10:00 P.M.) for 14 consecutive days of either saline or an escalating dose of morphine, in a pattern based on previously established selfadministration doses of morphine (ranging from $3 \mathrm{mg} / \mathrm{kg}$ to $24 \mathrm{mg} / \mathrm{kg}$, i.p., cumulative dose per day) (Kruzich et al., 2003; Glass et al., 2005). Animals were killed $1 \mathrm{~h}$ after the final morphine injection to avoid withdrawal. Given that injected morphine sulfate has a half-life of 2-4 h, morphine was, most likely, still physiologically active in the animals' systems at the time they were killed.

\section{Tissue preparation}

Rats were deeply anesthetized with sodium pentobarbital $(120 \mathrm{mg} / \mathrm{kg}$, i.p.; Sigma) and perfused through the ascending aorta with $20 \mathrm{ml}$ of heparin $(1000 \mathrm{U} / \mathrm{ml})$ in saline (American Pharmaceutic Partners) followed by $50 \mathrm{ml}$ of $3.75 \%$ acrolein (Polysciences) in 2\% paraformaldehyde in $0.1 \mathrm{M}$ phosphate buffer, and finally $200 \mathrm{ml}$ of $2 \%$ paraformaldehyde in $0.1 \mathrm{~m}$ phosphate buffer (Sigma). The brains were removed and cut into 4-5 mm coronal blocks that were postfixed in $2 \%$ paraformaldehyde for $30 \mathrm{~min}$, then sliced to $40 \mu \mathrm{m}$ sections on a Leica Vibratome VT1000 in chilled $0.1 \mathrm{~m}$ phosphate buffer. The collected vibratome sections were placed in a storage solution $(30 \%$ sucrose, $30 \%$ ethylene glycol in $0.05 \mathrm{~m}$ phosphate buffer, $\mathrm{pH} 7.4$ ) at $-20^{\circ} \mathrm{C}$ until used for immunolabeling of GluR1 and/or TH.

\section{Antisera}

A rabbit polyclonal antiserum against FG was commercially obtained from Millipore. This antiserum has been used extensively for identification of the injection sites and retrograde labeling of FG in many brain regions including the VTA (Van Bockstaele et al., 1994; Van Bockstaele and Pickel, 1995; Carr and Sesack, 2000).

GluR1 immunolabeling was achieved using an affinity purified rabbit polyclonal antiserum raised against a 15 aa peptide sequence corresponding to the $\mathrm{C}$ terminus of rat GluR1 AMPA subunit (Millipore). The GluR1 antiserum is well characterized by immunolabeling and Western blot analysis, which shows that this antiserum recognizes a single band of $110 \mathrm{kDa}$ corresponding to the GluR1 subunit with no cross-reaction with GluR2-GluR4 subunits (Siegel et al., 1995; Aicher et al., 2002; Glass et al., 2005).

The mouse monoclonal antibody raised against the rate-limiting catecholamine-synthesizing enzyme $\mathrm{TH}$ was commercially obtained from Immunostar. This antiserum exclusively recognizes TH (molecular weight, $60 \mathrm{kDa}$ ) and not other catecholamine-synthesizing enzymes (Garzón and Pickel, 2001; Lessard and Pickel, 2005).

\section{Immunocytochemistry}

Coronal sections of the VTA, mPFC, and NAc of FG-injected animals were coprocessed using immunoperoxidase labeling for the detection of FG. Coronal sections of tissue containing the VTA of morphine and saline-injected animals were coprocessed using a dual immunogoldsilver method for the detection of the GluR1 subunit of the AMPA glutamate receptor and immunoperoxidase detection of $\mathrm{TH}$. Coprocessing decreased the potential variability in labeling between experimental groups. The pre-embedding dual-labeling protocol used in the present study was adapted from that of Chan et al. (1990). In preparation for immunolabeling, sections of tissue containing the VTA were placed in $1 \%$ sodium borohydride in $0.1 \mathrm{~m}$ phosphate buffer to remove excess aldehydes, then freeze-thawed to enhance penetration of immunoreagents. For this, the tissue was incubated in a cryoprotectant solution ( $25 \%$ sucrose and $2.5 \%$ glycol in $0.05 \mathrm{~m}$ phosphate buffer), then immersed successively in liquid Freon, liquid nitrogen, and room temper- 
ature $0.1 \mathrm{~m}$ phosphate buffer. Tissue sections were rinsed $(0.1 \mathrm{M}$ phosphate buffer followed by $0.1 \mathrm{~m}$ Tris-buffered saline (TBS; pH 7.4) and incubated in $0.5 \%$ bovine serum albumin (BSA) in TBS to minimize nonspecific labeling. The tissue was then incubated for $42 \mathrm{~h}(24 \mathrm{~h}$ at room temperature and $18 \mathrm{~h}$ at $4^{\circ} \mathrm{C}$ ) in a primary antibody solution containing mouse anti-TH $(1: 50,000)$ and rabbit anti-GluR1 $(1: 150)$ antisera in $0.1 \%$ BSA in TBS. For immunoperoxidase detection of both FG and TH, the avidin-biotin complex (ABC) method was used. Sections were incubated for $30 \mathrm{~min}$ in biotinylated goat anti-rabbit (FG) or horse antimouse (TH) IgG (both 1:400) and then a 1:200 ABC solution (Vector Laboratories). The peroxidase reaction product was visualized with $0.022 \% 3,3^{\prime}$-diaminobenzidine (Aldrich), and $0.003 \% \mathrm{H}_{2} \mathrm{O}_{2}$ in TBS for 6 min. For immunogold-silver visualization of GluR1 immunoreactivity, tissue sections were incubated for $2 \mathrm{~h}$ in goat anti-rabbit colloidal gold ( 1 $\mathrm{nm}$ ) IgG (1:50; GE Healthcare), fixed in 2\% gluteraldehyde, and enhanced with a silver solution (IntenS-EM kit; GE Healthcare) for $7 \mathrm{~min}$.

The tissue was postfixed with $2 \%$ osmium tetroxide in $0.2 \mathrm{M}$ phosphate buffer for $1 \mathrm{~h}$ and then dehydrated through a series of ethanols $(30,50$, $70,95,100 \%), 100 \%$ propelyne oxide, then a 50:50 mixture of propylene oxide and EMbed 812 Epon substitute (Electron Microscopy Supply) overnight. The following day, the sections were incubated in the Epon substitute for $2 \mathrm{~h}$, then embedded in it between two sheets of Aclar plastic and placed in an oven $\left(60^{\circ} \mathrm{C}\right)$ for $24 \mathrm{~h}$.

We chose pre-embedded gold-silver immunocytochemistry to analyze the subcellular distribution of GluR1 labeling because this technique preserves the necessary fine structural details such as extrasynaptic membranes, which can be lost during the plastic embedding process (Adams et al., 2002). The pre-embedding method for immunogold also avoids spurious attachment of gold particles to the plastic, which often results in significant background labeling with postembedding techniques (Leranth and Pickel, 1989). Despite these advantages, the pre-embedding method may underestimate receptor proteins within the postsynaptic portions of the synapse. However, this limitation would be expected to apply equally to both saline- and morphine-treated tissue, making comparisons of synaptic labeling between conditions appropriate.

\section{Selection and sectioning of VTA tissue}

The PB and PN subdivisions of the VTA were separately isolated from the flat-embedded tissue (see Fig. $1 D$, trapezoids) by comparing the distributions of FG (see Figs. $1 A$ and $1 \mathrm{~B}$ ) and TH (Fig. $1 C$ ) immunoreactivity in reference to landmark structures identified in a rat brain atlas (Paxinos and Watson, 1986). We selected rostral to medial aspects of the VTA (ranging from -5.2 to $-5.3 \mathrm{~mm}$ from bregma) based on the greatest density of TH-immunoreactive cells. However, it is important to note that there are differences in the ratio of dopaminergic and GABAergic neurons throughout the rostral to caudal aspects of VTA (Olson and Nestler, 2007), and the rewarding effects of morphine are mediated from more caudal regions of the VTA where there is a higher proportion of GABAergic neurons (Olson et al., 2005; Olson and Nestler, 2007). Therefore, changes in GluR1 localization in more caudal regions of the VTA may be different from those reported here. However, the majority of changes in GluR1 localization occurred in dopaminergic dendrites of the VTA, which are more prevalent in the regions selected for the present study.

Ultrathin sections $(70 \mathrm{~nm})$ were cut from the isolated tissue on an ultratome (Leica). The same method was used to cut each block of tissue to ensure that similar levels of tissue were examined, minimizing labeling variability (see below) caused by differences in penetration of the antisera. First, a glass knife was used to align the tissue into an equal cutting plane and to remove excess embedding material from the surface of the tissue. No tissue was collected using the glass knife. As soon as any tissue was evident at the cutting surface, the glass knife was exchanged for a diamond knife (Diatome) which was used to cut ultrathin sections of tissue. These sections were collected on 400-mesh copper grids (Electron Microscopy Science). For each block of tissue, five copper grids were collected, containing two to three sections of tissue on each grid. Thus, the total depth of tissue collected was $0.7-1.0 \mu \mathrm{m}$ from the surface of the flat-embedded tissue, where optimal penetration of immunoreagents occurs. The sections were counterstained with uranyl acetate and lead ci- trate (Reynolds, 1963) and examined with a Phillips CM-10 electron microscope (FEI). The microscopic images were captured with an Advanced Microscopy Techniques Advantage HR/HR-B CCD camera system.

\section{Data analysis}

A total tissue area of $95,157 \mu \mathrm{m}^{2}$ (2436 micrographs at 13,500-25,000X magnification) was examined from the VTA of 12 rats in four treatment groups. Neuronal or glial profiles, that is, individual cross-sectioned structures within a given neuropil, which contained one or more gold particles, were considered labeled with immunogold. A minimal false positive identification of labeled profiles when using this criterion was assured by examining the percentage of gold particles overlying myelin which is not known to express AMPA GluR1 subunits, thus serving as a control for spurious gold-silver deposits. In individual profiles, the gold particles were characterized by location, such as contact with the plasma membrane, postsynaptic density, or other cytoplasmic structures. Peroxidase-immunoreactive profiles were defined as having an electron density considerably greater than that seen in comparable structures in the surrounding neuropil. Classification of all of the labeled profiles was determined by criteria from the study by Peters et al. (1991).

The parameters used for between-groups comparison include (1) profile size, (2) GluR1 immunogold distribution, (3) GluR1 synaptic analysis, and (4) TH immunoreactivity. To verify that the tissue used for analysis was selected at similar levels, a within-groups analysis was completed and revealed no significant difference in gold labeling between individual animals within each treatment group $\left(F_{(2,870)}=1.52 ; p>\right.$ $0.05)$. A power analysis of the significant parametric tests was completed to evaluate confidence of the results and to ensure that adequate sample sizes were used. Significant findings had power values ranging from 0.749 to 0.945 .

Profile size. The profile area, perimeter, average diameter, and form factor were measured for each profile (total of 5362 profiles; 2751 in the parabrachial VTA and 2611 in the paranigral VTA) using Microcomputer Image Device software (MCID; Imaging Research). A cluster analysis was performed to statistically sort the profiles by size and Student's $t$ tests were conducted to evaluate size differences between the PB and PN VTA regions.

GluR1 immunogold labeling. GluR1 gold particles were characterized by their location within the profile, such as whether they were in contact with the plasma membrane or within the cytoplasm. These numbers were combined with size measurements obtained from the MCID program to give the following measures of gold particle density: the number of GluR1 gold particles on the plasma membrane divided by the perimeter of the profile, the cytoplasm divided by the area of the profile, and the total number (cytoplasmic plus plasmalemmal) of gold particles divided by the area of the profile. The data were analyzed using a two-factor (drug $\times$ dendritic size) ANOVA followed by post hoc analysis using Tukey's test.

GluR1 synaptic analysis. Synaptic labeling was examined by quantifying the number of GluR1-labeled synapses out of the total number of synapses per experimental group. In addition, the number of GluR1 gold particles at postsynaptic densities was counted. The gold particles at postsynaptic densities were analyzed separately and not included in plasmalemmal counts (described above). The ratio of synaptic labeling was evaluated using $\chi^{2}$ analyses and differences in the number of synaptic GluR1 gold particles was analyzed with a single factor ANOVA.

Multivesicular bodies analysis. AMPA receptors are quite mobile and are rapidly inserted into and removed from postsynaptic membranes (Ehlers, 2000). Multivesicular bodies (MVBs) are late endosomal structures involved in receptor degradation and recycling and have been shown to contain GluR1-labeled AMPA receptors (Baude et al., 1994). Thus, the number of MVBs within labeled profiles was determined and correlated with synaptic GluR1 labeling.

TH immunoreactivity. Profiles with GluR1 labeling were characterized as containing or lacking TH immunoperoxidase, and for most analyses the single-labeled and dual-labeled profiles were considered separately. TH-peroxidase-immunoreactive neurons in the VTA can be divided into two groups, each with a distinct TH labeling intensity (Bayer and Pickel., 

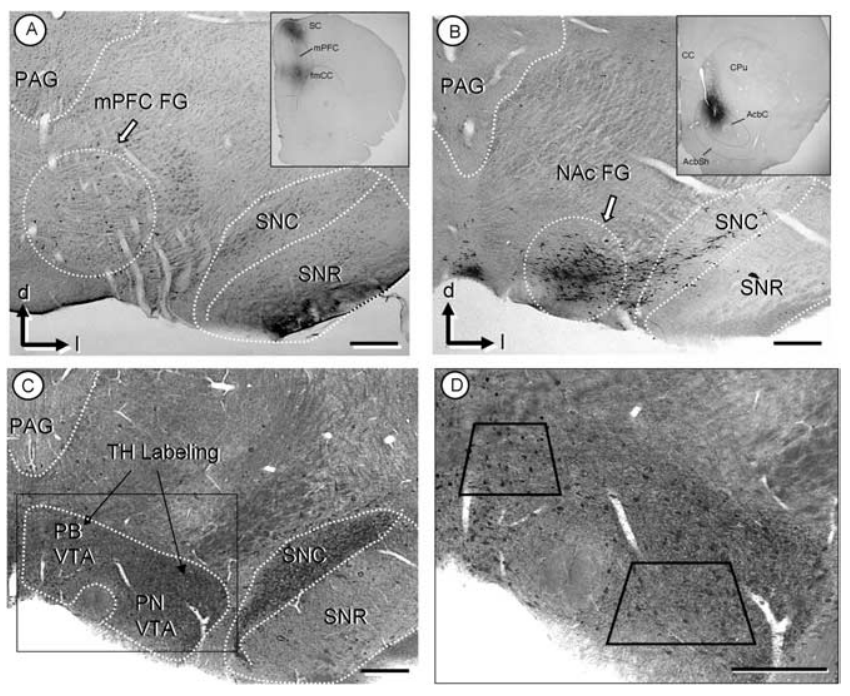

Figure 1. $\quad A, B$, Light micrographs showing retrogradely labeled neurons in VTA. After injection of the retrograde tracer, $\mathrm{FG}$, into the $\mathrm{MPFC}$ (inset, $\boldsymbol{A}$ ), peroxidase-labeled neurons are mainly located within the parabrachial subdivision of the VTA (dotted circle in $A$ ). After FG injection to the NAC (inset, $\boldsymbol{B}$ ), retrogradely labeled neurons are located within the paranigral VTA (dotted circle in $\boldsymbol{B}$ ). $\boldsymbol{C}, \boldsymbol{D}$, Light micrographs of plastic embedded TH and GluR1 labeled tissue. Both the PB and PN regions of the VTA show peroxidase labeling for TH, whereas the GluR1-gold is not discernable at this magnification (C). A higher magnification (D) includes trapezoids demarcating the areas used for electron microscopic analysis of the PB and PN VTA. CPu, Caudate-putamen; fmcc, foceps minor corpus callosum; mp, mammilary peduncle; PAG, periaqueductal gray; $\mathrm{SC}$, somatosensory cortex; $\mathrm{SNc}$, substantia nigra zona compacta; $\mathrm{SNr}$, substantia nigra zona reticulate; d, dorsal; l, lateral. Scale bars, $500 \mu \mathrm{m}$.

1990) and GABAergic inputs (Bayer and Pickel, 1991). Chronic morphine has been shown to increase TH levels in the VTA (Beitner-Johnson and Nestler, 1991; Spiga et al., 2003). Thus, TH-peroxidase-labeled profiles in the VTA were sorted into two categories (intense or light) and the ratio of intensely to lightly labeled TH dendrites after acute and chronic morphine was examined using $\chi^{2}$ analyses. The classification of "intense" or "light" was based on qualitative assessment of the observed electron density to neighboring profiles in the surrounding neuropil.

\section{Results}

\section{Fluorogold retrograde labeling}

The FG injections into the mPFC produced retrograde FG labeling predominantly in the PB VTA (Fig. 1A). In contrast, the majority of VTA neurons retrogradely labeled after FG injection in the NAc were located in the PN VTA (Fig. $1 B$ ), supporting previous findings by Carr and Sesack (2000), who also used FG to reveal VTA cortical projections. There was some degree of overlap in the distribution of the VTA neurons that project to each region, consistent with known collateralization of the VTA projection neurons (Van Bockstaele et al., 1994). The overlapping distributions were more evident with retrograde transport from the $\mathrm{mPFC}$, which resulted in sparse retrograde labeling in the PN VTA in addition to the labeling in the PB VTA. Injections of FG in the NAc resulted in more abundant FG immunoperoxidase labeling in the PN VTA, and produced some retrograde transport in the PB VTA.

\section{GluR1 immunogold distribution}

In both the PB and PN VTA, GluR1 immunogold labeling was mainly in dendrites, although labeling was also detected in somata and to a lesser extent in axons and terminals (Fig. 2A,B). GluR1 labeling was evident in dendritic profiles with or without TH immunoreactivity in each of these regions (Fig. 2A,B).

GluR1 immunogold-labeled dendrites were abundant
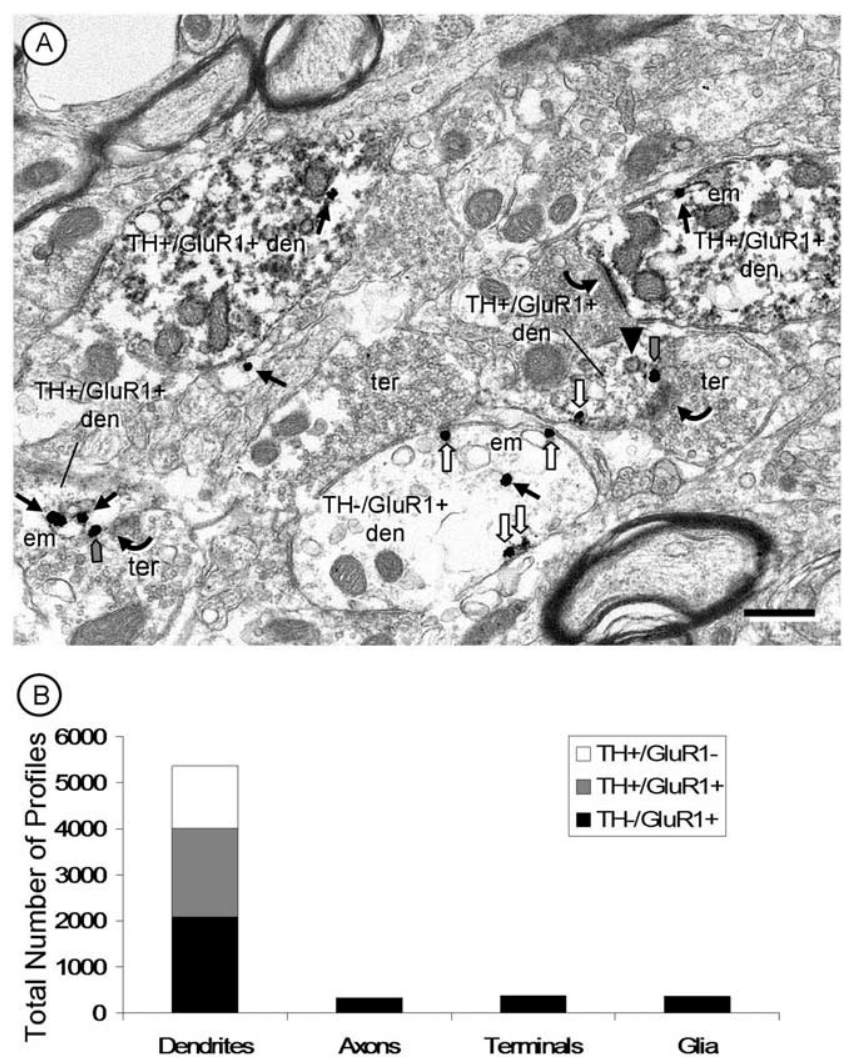

Figure 2. A, A representative electron micrograph of the PB VTA showing GluR1 gold labeling in both dopaminergic (TH+/GluR1+ den) and nondopaminergic (TH-/GluR1+ den) dendrites of the VTA. Within these dendrites, GluR1 is present within the cytoplasm (black arrows), often associated with endomembranes (em). GluR1 is also on the plasma membrane (white arrows) and at excitatory-type postsynaptic densities (gray arrows). A clathrin-coated endosome (black arrowhead) can be seen near an excitatory-type synapse (gray arrow) with a GluR1-labeled gold particle. Small axons and axon terminals (ter) or glial processes were more rarely immunolabeled for GluR1 but not TH. Scale bar, $500 \mathrm{~nm}$. B, Quantification of the distribution of GluR1 and TH in the VTA reveals a predominance of both labels in dendrites.

throughout the VTA. An average of $56 \pm 6 \%$ of dendritic profiles in a given micrograph showed GluR1 labeling, with no significant differences in the percentage of labeled dendrites between treatment groups $\left(\chi_{(3)}^{2}=0.23 ; p>0.05\right)$. This percentage, however, is most likely an underestimate of the ratio of labeled (to unlabeled) dendrites in a given neuropil. Within longitudinally cut dendrites, the distance between gold particles ranges from $0.5-3$ $\mu \mathrm{m}$, a distance that is much greater than the $70 \mathrm{~nm}$ thickness of the ultrathin sections of tissue. Thus, when a dendrite is cut transversely into thin sections, there may be several profiles from each GluR1-containing dendrite that show no GluR1 immunogold particles.

The GluR1- and/or TH-labeled dendritic profiles were generally small to medium in size. GluR1 immunogold particles were mainly in the cytoplasm, where they appeared to associate with endomembranes. Other gold particles were in contact with the plasma membrane (Fig. 2), and these were more common in small, presumably more distal dendrites. Dendritic GluR1 labeling was highly selective for particular dendrites and was absent from other similar profiles within the same neuropil.

Of all of the plasmalemmal GluR1 immunogold particles $(n=$ 4457 ), $57 \%$ were on portions of the membrane opposed to glia, whereas the remaining $43 \%$ were located at, or near, synaptic contacts from axon terminals. Of the synapse-associated GluR1 immunogold particles $(n=1922), 91 \%$ were located at the 
postsynaptic densities of asymmetric synapses, and 9\% were located in postsynaptic densities of apparent symmetric synapses. These apparent symmetric synapses may also represent peripheral portions of asymmetric synapses where the postsynaptic membrane specialization is less notably dense. The morphology of these synapses is of interest because a link between synaptic structure and function has been shown (Eccles, 1964; Peters et al., 1991). Asymmetric synapses are generally thought to be excitatory-type synapses because they apposed to glutamatergic terminals (Rollenhagen and Lübke, 2006) and are associated with excitatory proteins (Carlin et al., 1980), whereas symmetric synapses are generally thought to be inhibitory because they are apposed to GABAergic terminals (Sesack and Pickel, 1995; Steffensen et al., 1998) and are potentially linked with inhibitory proteins (Carlin et al., 1980).

\section{Size-dependent dendritic immunolabeling}

The majority of all labeled dendrites (GluR1 and/or TH from all treatment groups) were small in diameter (range of 0.04-0.7 $\mu \mathrm{m}$ ) and comprised $56.7 \%$ of the total number of dendrites. Medium dendrites made up 35.5\% of all labeled dendrites, and these ranged from 0.7 to $1.3 \mu \mathrm{m}$ average diameter. Only a small portion $(7.8 \%)$ of the total number of labeled dendrites was $>1.3$ $\mu \mathrm{m}$ in average diameter. These large dendrites were the most variable in size and ranged from 1.4 to $4.0 \mu \mathrm{m}$ in average diameter, with the largest likely including portions of the labeled somata.

The average cross-sectional diameters (size) of labeled dendrites were significantly different between the PN and PB VTA subregions $\left(t_{(5360)}=3.33 ; p<0.05\right)$. On average, the PN VTA dendrites were smaller and slightly less often contained TH immunoreactivity than those in the PB VTA. Nondopaminergic dendrites with GluR1 labeling $(\mathrm{TH}-/ \mathrm{GluR} 1+)$, however, were significantly larger than dopaminergic dendrites $(\mathrm{TH}+/$ GluR1 +$)$ in both the PN $\left(F_{(5,2750)}=65.51 ; p<0.001\right)$ and $\mathrm{PB}$ $\operatorname{VTA}\left(F_{(5,2610)}=32.55 ; p<0.001\right)$.

\section{Morphine effect on dendritic size}

Acute morphine administration produced a significant increase, above saline controls, in the average diameter of dopaminergic $(\mathrm{TH}+/$ GluR1 + labeled) dendrites in both regions of the VTA $\left(\mathrm{PB}: F_{(1,938)}=19.88, p<0.001 ; \mathrm{PN}: F_{(1,875)}=44.43, p<0.001\right)$ and in nondopaminergic ( $\mathrm{TH}-/ \mathrm{GluR} 1+$ labeled) dendrites exclusively in the PN VTA $\left(F_{(1,512)}=5.08 ; p<0.05\right)$ (Fig. 3$)$. There was no significant difference between acute morphine and saline groups in size of nondopaminergic ( $\mathrm{TH}-/ \mathrm{GluR} 1+$ labeled) dendrites of the PB VTA, although there was a trend toward increased size after acute morphine $\left(F_{(1,519)}=3.50 ; p>0.05\right)$ (Tables 1,2 , Fig. 3).

After chronic intermittent-escalating morphine administration, only the dopaminergic $(\mathrm{TH}+/ \mathrm{GluR} 1+$ labeled $)$ dendrites showed size differences from saline controls; the mean diameter of these dendrites was greater in the PB VTA $\left(F_{(1,455)}=5.34 ; p<\right.$ $0.05)$ and smaller in the PN VTA $\left(F_{(1,536)}=7.99 ; p<0.01\right)$. Chronic morphine administration did not produce any significant size changes in the nondopaminergic (TH-/GluR1+ labeled) dendrites, which were similar in size to saline controls in both the PB $\left(F_{(1,698)}=1.37 ; p>0.05\right)$ and PN VTA $\left(F_{(1,732)}=\right.$ $1.43 ; p>0.05$ ) (Fig. 3 ).

The changes in dendrite diameter observed in both regions of the VTA may reflect the redistribution of GluR1 gold particles within these dendrites (i.e., more smaller/larger dendrites analyzed because of the location of GluR1 labeling) or a morpholog-
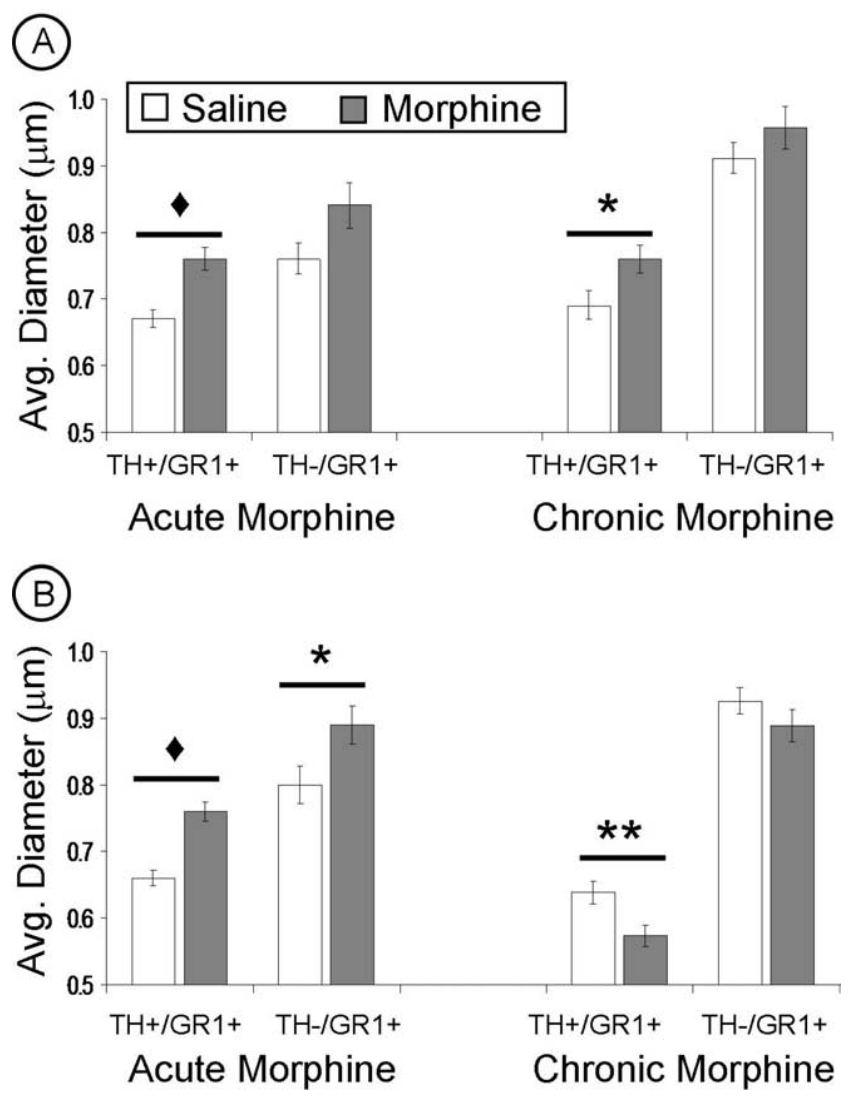

Figure 3. $A, B$, Quantification of the effect of acute and chronic morphine on mean size of both dopaminergic $(\mathrm{TH}+/ \mathrm{GR} 1+)$ and nondopaminergic $(\mathrm{TH}-/ \mathrm{GR} 1+)$ dendrites within the parabrachial $(\boldsymbol{A})$ and paranigral $(\boldsymbol{B})$ VTA after acute or chronic morphine. $\boldsymbol{A}$, In the PB VTA, either acute or chronic morphine administration results in an increase in the average diameter of dopaminergic (TH +/GR1 +) dendrites above saline controls. $\boldsymbol{B}$, In the PN VTA, acute morphine produced a significant increase in the average diameter of both dopaminergic $(\mathrm{TH}+/ \mathrm{GR} 1+)$ and nondopaminergic $(\mathrm{TH}-/ \mathrm{GR} 1+)$ dendrites, whereas chronic morphine produced a decrease in dopaminergic $(\mathrm{TH}+/ \mathrm{GR} 1+$ ) dendrites, compared with saline controls. $p<0.001$; ${ }^{* *} p<0.01 ;{ }^{*} p<0.05$. Error bars indicate SEM.

ical change after morphine administration. To examine this question further, the average diameter of all TH-labeled dendrites within a given neuropil, regardless of the presence of GluR1 gold particles, were measured for each VTA region. After acute morphine, there was a significant increase in the average diameter of dopaminergic dendrites in both VTA regions. With chronic morphine administration, there was a significant increase in the PB VTA and a significant decrease in the PN VTA in the average diameter of all dopaminergic dendrites (GluR1 labeled or not). These findings support the conclusion of a morphological change, which is consistent with reported neurofilament changes in VTA neurons with repeated morphine administration (Guitart et al., 1992; Sklair-Tavron et al., 1996). However, we cannot completely rule out the potential contribution of changes in receptor localization to the reported size differences, because all micrographs were taken in regions where GluR1 labeling was evident. Thus, we speculate that both factors may play a role in the morphine-linked changes in dendrite diameter

\section{Acute morphine effects on GluR1 dendritic distribution} GluR1 in TH-labeled dendrites

In dopaminergic $(\mathrm{TH}+/$ GluR1 + labeled) dendrites within the PB VTA, a single injection of morphine resulted in a significant decrease, below saline controls, in the average cytoplasmic den- 
Table 1. TH and GluR1 dual-labeled dendrites (significant changes from saline controls)

\begin{tabular}{|c|c|c|c|c|c|c|c|}
\hline VTA Region & $\begin{array}{l}\text { Morphine } \\
\text { paradigm }\end{array}$ & $\begin{array}{l}\text { Cytoplasmic dendritic } \\
\text { labeling }\end{array}$ & $\begin{array}{l}\text { Plasmalemmal dendritic } \\
\text { labeling }\end{array}$ & Synaptic labeling & MVB & $\begin{array}{l}\text { Dendritic } \\
\text { size }\end{array}$ & TH immunoreactivity \\
\hline PB VTA & $\begin{array}{l}\text { Acute } \\
\text { Chronic }\end{array}$ & $\begin{array}{l}\downarrow \text { small, medium } \\
\text { No change }\end{array}$ & $\begin{array}{c}\uparrow \text { small } \\
\text { No change }\end{array}$ & $\begin{array}{l}\uparrow \# \text { of labeled synapses } \\
\uparrow \text { \# of labeled synapses; } \\
\uparrow \text { \# of gold particles }\end{array}$ & $\begin{array}{l}\downarrow \\
\downarrow\end{array}$ & $\begin{array}{l}\uparrow \\
\uparrow\end{array}$ & $\begin{array}{l}\downarrow \\
\uparrow\end{array}$ \\
\hline PN VTA & $\begin{array}{l}\text { Acute } \\
\text { Chronic }\end{array}$ & $\begin{array}{l}\downarrow \text { small, medium } \\
\text { No change }\end{array}$ & $\begin{array}{l}\text { No change } \\
\text { No change }\end{array}$ & $\begin{array}{l}\text { No change } \\
\uparrow \text { \# of labeled synapses }\end{array}$ & $\begin{array}{l}\text { No change } \\
\downarrow\end{array}$ & $\uparrow$ & $\begin{array}{l}\text { No change } \\
\uparrow\end{array}$ \\
\hline
\end{tabular}

$\uparrow$, Increase; $\downarrow$, decrease; \#, number.

Table 2. GluR1 single-labeled dendrites (significant changes from saline controls)

\begin{tabular}{|c|c|c|c|c|c|c|}
\hline VTA Region & Morphine paradigm & Cytoplasmic dendritic labeling & Plasmalemmal dendritic labeling & Synaptic labeling & MVB & Dendritic size \\
\hline PB VTA & $\begin{array}{l}\text { Acute } \\
\text { Chronic }\end{array}$ & $\begin{array}{l}\downarrow \text { small, medium } \\
\text { No change }\end{array}$ & $\begin{array}{l}\uparrow \text { small } \\
\text { No change }\end{array}$ & $\begin{array}{l}\uparrow \text { \# of labeled synapses } \\
\uparrow \text { \# of labeled syn; } \\
\uparrow \text { \# of gold particles }\end{array}$ & $\begin{array}{l}\downarrow \\
\downarrow\end{array}$ & $\begin{array}{l}\text { No change } \\
\text { No change }\end{array}$ \\
\hline PN VTA & $\begin{array}{l}\text { Acute } \\
\text { Chronic }\end{array}$ & $\begin{array}{l}\downarrow \text { small, medium } \\
\text { No change }\end{array}$ & $\begin{array}{l}\text { No change } \\
\text { No change }\end{array}$ & $\begin{array}{l}\uparrow \text { \# of labeled synapses } \\
\uparrow \text { \# of labeled synapses }\end{array}$ & $\downarrow$ & $\begin{array}{l}\uparrow \\
\text { No change }\end{array}$ \\
\hline
\end{tabular}

$\uparrow$, Increase; $\downarrow$, decrease; \#, number.

Acute Saline

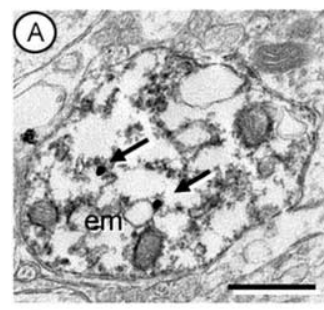

(C)

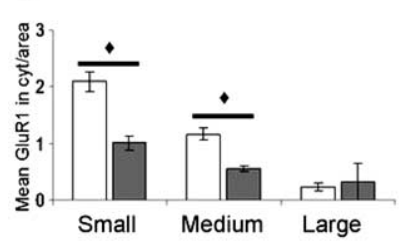

Figure 4. Acute morphine produces redistribution of GluR1 labeling. $A, B$, GluR1-gold particles in small dopaminergic ( $(\mathrm{TH}+/ \mathrm{GluR1}+$ ) dendrites have a predominantly cytoplasmic distribution (black arrows) in saline controls $(\boldsymbol{A})$ but shift to a more plasmalemmal (white arrows) distribution ( $\boldsymbol{B}$ ) after acute morphine administration. $\boldsymbol{C}, \boldsymbol{D}, \mathrm{GluR1}$ immunogold labeling in dopaminergic (TH+/GluR1+) dendrites decreases in cytoplasm $(\boldsymbol{C})$ and increases at the plasmalemma $(\boldsymbol{D})$ after acute morphine administration. $p<0.001 ;{ }^{*} p<0.05$. Scale bars, $500 \mathrm{~nm}$. Error bars indicate SEM. em, Endomembrane.

sity $\left(F_{(1,938)}=37.46 ; p<0.001\right)$ and total (cytoplasmic and plasmalemmal $)$ density $\left(F_{(1,938)}=28.66\right.$; $\left.p<0.001\right)$ of GluR1 immunogold particles in small and medium dendrites. There was a concurrent significant increase in the plasmalemmal density of GluR1 gold particles in small $(\mathrm{TH}+/ \mathrm{GluR} 1+$ labeled) dendrites only $\left(F_{(1,938)}=3.34 ; p<0.05\right)$ (Tables 1, 2, Fig. 4$)$.

A similar effect of acute morphine on GluR1-immunogold particle distribution was seen in dopaminergic $(\mathrm{TH}+/ \mathrm{GluR} 1+$ labeled) dendrites of the PN VTA. After acute morphine administration, there was a significant decrease in both cytoplasmic $\left(F_{(1,875)}=20.97 ; p<0.001\right)$ and total $\left(F_{(1,875)}=21.13 ; p<0.001\right)$ GluR1 particle density in small and medium sized dendrites, compared with saline controls. A slightly greater plasmalemmal density of GluR1 gold particles was seen in small dopaminergic $(\mathrm{TH}+/ \mathrm{GluR} 1+$ labeled $)$ dendrites of rats receiving acute morphine compared with saline controls, however this difference was not statistically significant $\left(F_{(1,875)}=1.04 ; p>0.05\right)$ (supplemental Fig. 1, available at www.jneurosci.org as supplemental material). These observations suggest a plasmalemmal redistribution of GluR1-containing AMPA receptors at more distal portions of dopaminergic dendrites, where more excitatory synaptic contacts are generally found, after acute morphine administration.

GluR1 in dendrites without TH immunoreactivity

In the PB VTA, nondopaminergic ( $\mathrm{TH}-/ \mathrm{GluR} 1+$ labeled) dendrites showed no significant treatment-specific differences between acute morphine and saline treatment groups in cytoplasmic $\left(F_{(1,519)}=0.93 ; p>0.05\right)$ or total density of GluR1 gold particles $\left(F_{(1,519)}=0.22 ; p>0.05\right)$. There were, however, significant changes in plasmalemmal density after acute morphine that depended on dendritic size $\left(F_{(1,519)}=4.68 ; p<\right.$ $0.05)$. Compared with saline controls, animals that received acute morphine showed a decrease in the plasmalemmal density of GluR1-immunogold in small dendrites, but an increase in medium and large dendrites (Tables 1, 2). These observations suggest a redistribution of GluR1-containing AMPA receptors to more distal portions of the dendrite after a single injection of morphine.

In the PN VTA, nondopaminergic (TH-/GluR1+ labeled) dendrites showed no differences in GluR1 density after acute morphine. Specifically, there were no changes in cytoplasmic $\left(F_{(1,512)}=0.03 ; p>0.05\right)$, plasmalemmal $\left(F_{(1,512)}=1.70 ; p>\right.$ $0.05)$, or total $\left(F_{(1,512)}=1.03 ; p>0.05\right)$ density of GluR1 gold labeling compared with saline controls.

\section{Chronic intermittent escalating-dose morphine effects on GluR1 dendritic distribution}

GluR1 in TH-containing dendrites

After chronic morphine administration, dopaminergic $(\mathrm{TH}+/$ GluR1+ labeled) dendrites within the PB VTA were not significantly different from those in the saline control group in cytoplasmic $\left(F_{(1,455)}=3.36 ; p>0.05\right)$, plasmalemmal $\left(F_{(1,455)}=\right.$ $0.01 ; p>0.05)$, or total $\left(F_{(1,455)}=1.97 ; p>0.05\right)$ density of GluR1 immunogold particles. Similarly, in dopaminergic $(\mathrm{TH}+/$ GluR1+ labeled) dendrites of the PN VTA, chronic morphine, and saline groups showed no significant differences in cytoplas$\operatorname{mic}\left(F_{(1,525)}=1.09 ; p>0.05\right)$, plasmalemmal $\left(F_{(1,525)}=3.76\right.$; 
$p>0.05)$, or total $\left(F_{(1,525)}=1.49 ; p>0.05\right)$ GluR1 gold density (Tables 1, 2).

\section{GluR1 in dendrites without TH immunoreactivity}

Rats receiving chronic intermittent-escalating doses of morphine showed a significant increase in plasmalemmal density of GluR1 gold labeling $\left(F_{(1,693)}=5.04 ; p<0.05\right)$ in medium nondopaminergic $(\mathrm{TH}-/$ GluR1 + labeled) dendrites of the PB VTA. These dendrites showed no other significant differences from saline controls, but there was a slight decrease in plasmalemmal labeling in small dendrites of the PB VTA. There were no significant changes in nondopaminergic $(\mathrm{TH}-/ \mathrm{GluR} 1+$ labeled) dendrites within the PN VTA (Tables 1,2).

\section{Effects of acute and chronic intermittent escalating morphine} on synaptic GluR1 distribution and relationship to MVBs In dopaminergic ( $\mathrm{TH}+/$ GluR1 + labeled) and nondopaminergic $(\mathrm{TH}-/$ GluR1 + labeled) dendrites of the PB VTA, an increase in the number of synapses labeled with GluR1 gold particles was seen both with acute morphine (TH+/GluR1+, $\chi^{2}=9.11, p<$ $\left.0.01 ; \mathrm{TH}-/ \mathrm{GluR} 1+, \chi^{2}=20.44, p<0.001\right)$ and with chronic morphine $\left(\mathrm{TH}+/ \mathrm{GluR} 1+, \chi^{2}=5.80, p<0.05\right.$; $\mathrm{TH}-/ \mathrm{GluR} 1+$, $\left.\chi^{2}=11.77, p<0.001\right)$ compared with saline controls (Fig. 5). Furthermore, chronic morphine also resulted in a significant increase in the number of GluR1 gold particles at each labeled synapse $\left(F_{(1,836)}=7.68 ; p<0.01\right)$. Thus, in the PB VTA, chronic intermittent-escalating morphine administration produced not only more synapses labeled with GluR1, but more GluR1 subunits at each synapse (Fig. 6).

In the PN VTA, in contrast, acute morphine administration produced no significant changes from saline controls in synaptic GluR1 labeling of dopaminergic (TH+/GluR1 + labeled) dendrites $\left(\chi^{2}=0.65 ; p>0.05\right)$. After chronic morphine, however, these dendrites showed a significant increase in the number of synapses labeled with GluR1 gold particles $\left(\chi^{2}=6.96 ; p<0.01\right)$ (Tables 1,2$)$. Thus, although chronic morphine administration produced little change in the plasmalemmal and cytoplasmic distribution of GluR1 AMPA receptors, it had a large impact on synaptic GluR1 distribution (see Discussion).

Interestingly, we observed a significant negative correlation $(r=-0.54 ; p<0.05)$ between synaptic GluR1 labeling and the number of MVBs: as the number of GluR1-labeled synapses increased, the number of MVBs found within these dendrites decreased. This occurred in dopaminergic $(\mathrm{TH}+/ \mathrm{GluR} 1+$ labeled $)$ and nondopaminergic ( $\mathrm{TH}-/$ GluR1 + labeled) dendrites with acute and chronic morphine administration in both regions of the VTA. The one exception to this correlation was that dopaminergic $(\mathrm{TH}+/$ GluR1 + labeled) dendrites of the PN VTA showed no significant changes in the number of MVBs after acute morphine administration; however, these dendrites did show a significant decrease in the number of MVBs after chronic morphine administration (Fig. 7). The inverse correlation between MVBs and synaptic GluR1 labeling suggests that MVBs may play a role, although indirect, in regulating AMPA receptors at excitatory synapses.

\section{Acute and chronic intermittent-escalating morphine effects on tyrosine hydroxylase immunoreactivity}

Dendrites in both the PN and PB VTA of all treated groups showed notable differences in the density of the peroxidase immunoreaction product for TH. The difference in labeling was independent of the depth from the surface, because only the superficial portions of the tissue in contact with the plastic embed-
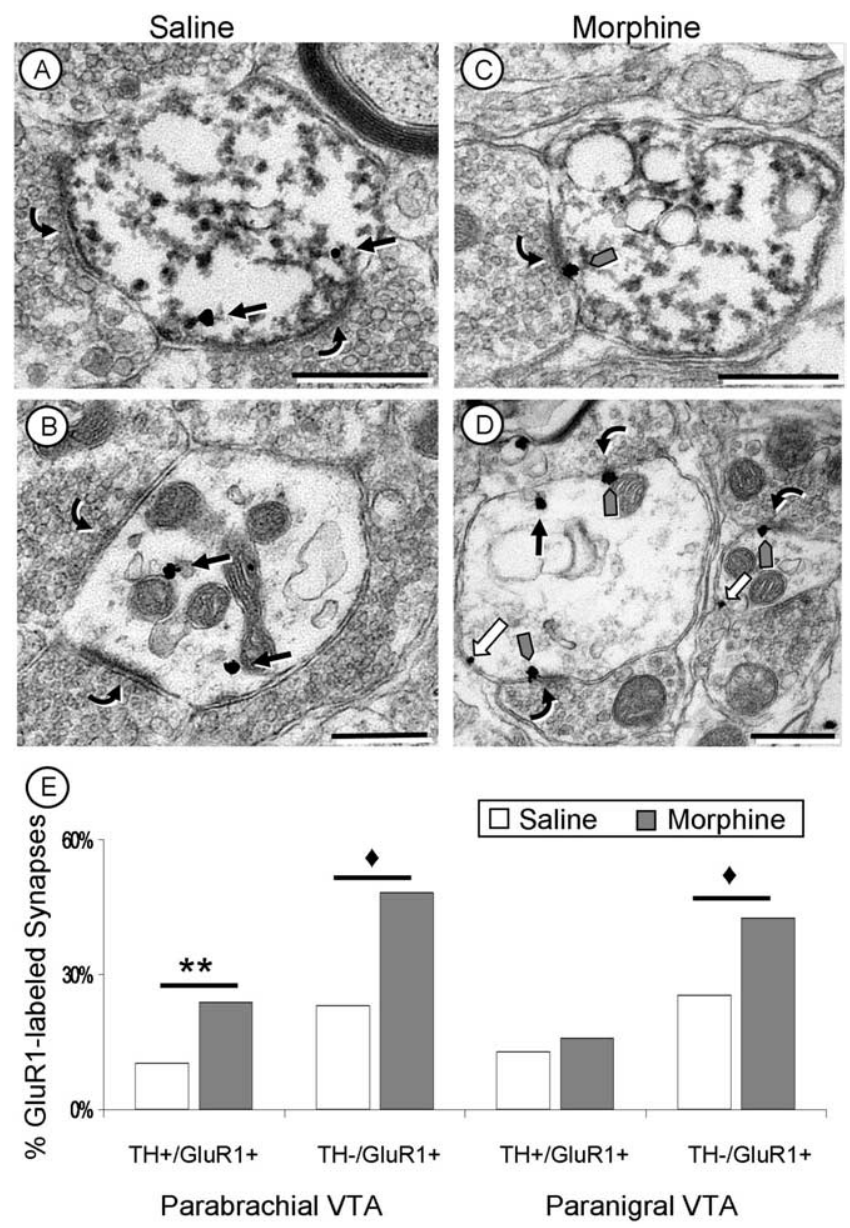

Figure 5. Acute morphine increases synaptic GluR1 labeling in the VTA. $A-D$, Electron micrographs of dopaminergic (TH+/GluR1+;A, C) and nondopaminergic (TH-/GluR1+; B, D) dendrites within the PB VTA. With saline administration $(\boldsymbol{A}, \boldsymbol{B})$, GluR1 labeling is cytoplasmic (black arrows) with no labeling at synaptic contacts (curved arrows). After a single injection of morphine $(\boldsymbol{C}, \boldsymbol{D})$, there is a significant increase in the number of excitatory-type synapses labeled with GluR1 immunogold particles (gray arrows) in both dopaminergic (TH $+/ \mathrm{GluR} 1+; \mathrm{C}$ ) and nondopaminergic (TH-/GluR1+;D) dendrites in the rat PB VTA. $\boldsymbol{E}$, Quantification of the number of synapses labeled with GluR1 gold after a single injection of morphine. GluR1-labeled synapses were more abundant in both dopaminergic $(\mathrm{TH}+/ \mathrm{GluR} 1+)$ and nondopaminergic (TH-/GluR1+) dendrites of the PB VTA but only in nondopaminergic (TH-/GluR1+) dendrites in the PN VTA. White arrows, Plasmalemmal GluR1 labeling. $p<0.001 ;{ }^{* *} p<0.01$. Scale bars, $500 \mathrm{~nm}$.

ding material was used in the analysis and different levels of TH peroxidase immunoreactivity were present within the same neuropil (Fig. 8). Acute morphine resulted in a significant decrease in the number of intensely labeled dopaminergic dendrites in the PB VTA only $\left(\chi^{2}=6.61 ; p<0.05\right)$ with no change in the PN VTA $\left(\chi^{2}=2.57 ; p>0.05\right)$ (Fig. 8). In contrast, a significantly greater number of intensely $\mathrm{TH}$-labeled dendritic profiles were seen in both PB $\left(\chi^{2}=5.89 ; p<0.05\right)$ and PN VTA $\left(\chi^{2}=6.30 ; p<0.05\right)$ (Fig. 8) of rats receiving chronic intermittent morphine compared with saline controls (Tables 1, 2).

\section{Discussion}

This study provides the first ultrastructural evidence that acute and chronic morphine administration results in region-specific changes in GluR1 distribution in dendrites in the rat VTA. The differential effects of acute and chronic morphine in VTA subdivisions, which have at least partially segregated cortical (PB VTA) and limbic (PN VTA) projections, have important implications 

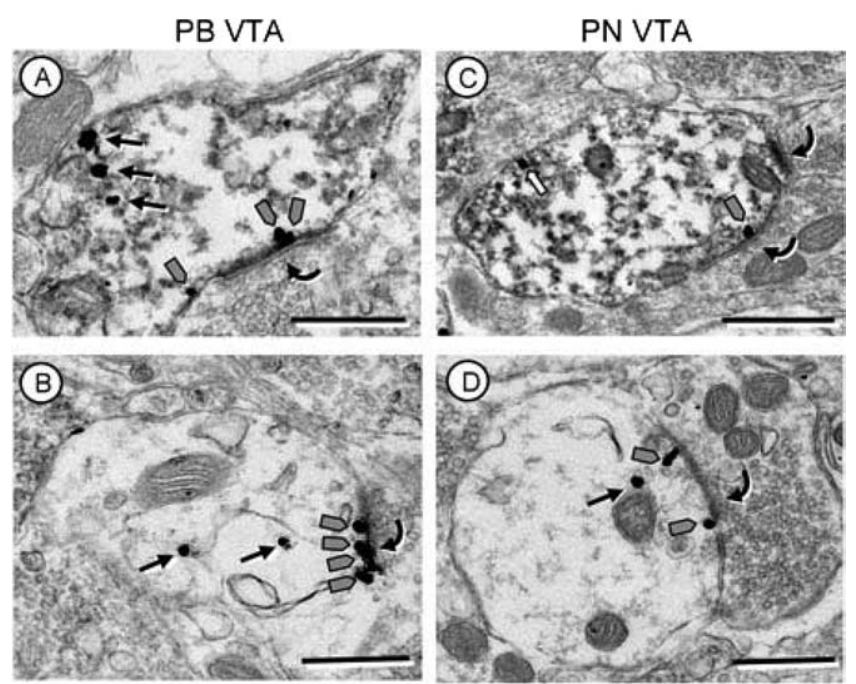

(ㄷ)
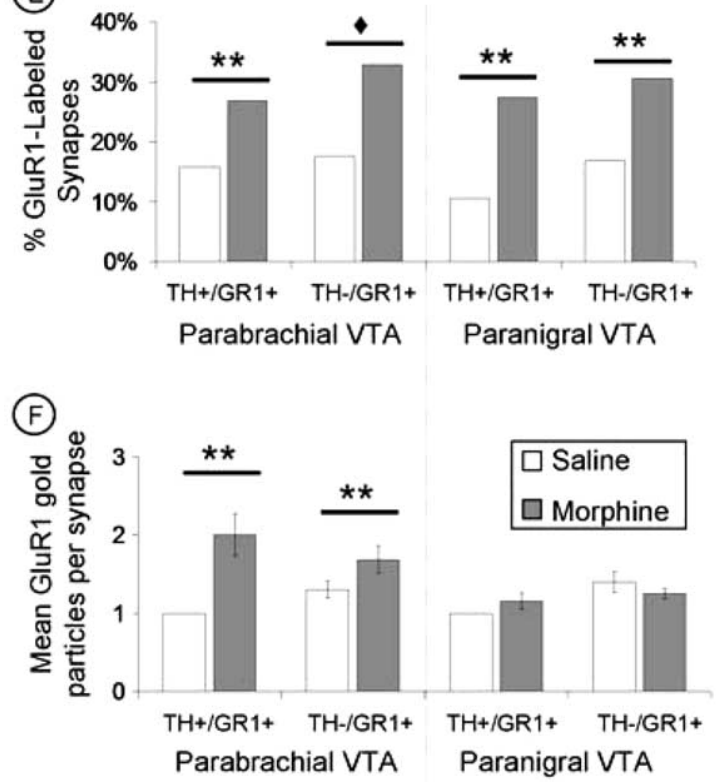

Figure 6. Chronic intermittent escalating-doses of morphine increased synaptic GluR1 labeling. $A-D$, Electron micrographs of dopaminergic (TH $+/ G R 1+; A, C$ and nondopaminergic $(\mathrm{TH}-/ \mathrm{GR} 1+; \boldsymbol{B}, \boldsymbol{D})$ dendrites within the PB $(\boldsymbol{A}, \boldsymbol{B})$ and PN $(\boldsymbol{C}, \boldsymbol{D})$ VTA after chronic intermittent escalating-doses of morphine. In the PBVTA $(\boldsymbol{A}, \boldsymbol{B})$, significantly more synapses are labeled with GluR1-gold particles, and there is also an increase in the number of GluR1 immunogold particles (gray arrows) at each labeled excitatory postsynaptic density (curved arrows) after chronic intermittent escalating-doses of morphine. In the PN VTA $(\boldsymbol{C}, \boldsymbol{D})$, there is an increase in the number of GluR1 labeled synapses (curved arrows) with no significant increase in the number of gold particles at each synapse (gray arrows). $\boldsymbol{E}, \boldsymbol{F}$, Quantification of increases in synaptic GluR1 labeling after chronic morphine administration. There is an increase in the percentage of GluR1 immunogold-labeled synapses in both the PB and PN VTA after chronic morphine administration (E). In contrast, only in the PB VTA is there a significant increase in the number of GluR1 immunogold particles at each synapse $(\boldsymbol{F})$ after chronic morphine. White arrows, Plasmalemmal GluR1 labeling. $p<0.001 ;{ }^{* *} p<0.01$. Scale bars, $500 \mathrm{~nm}$.

for understanding the adaptive mechanisms underlying opiate addiction (Fig. 9).

\section{Methodological considerations}

All sections from acute and chronic drug administration groups were coprocessed, and special care was taken to avoid sampling bias in either rostral-to-caudal tissue sections or depth from tissue surface. Furthermore, micrographs of the neuropil were col-
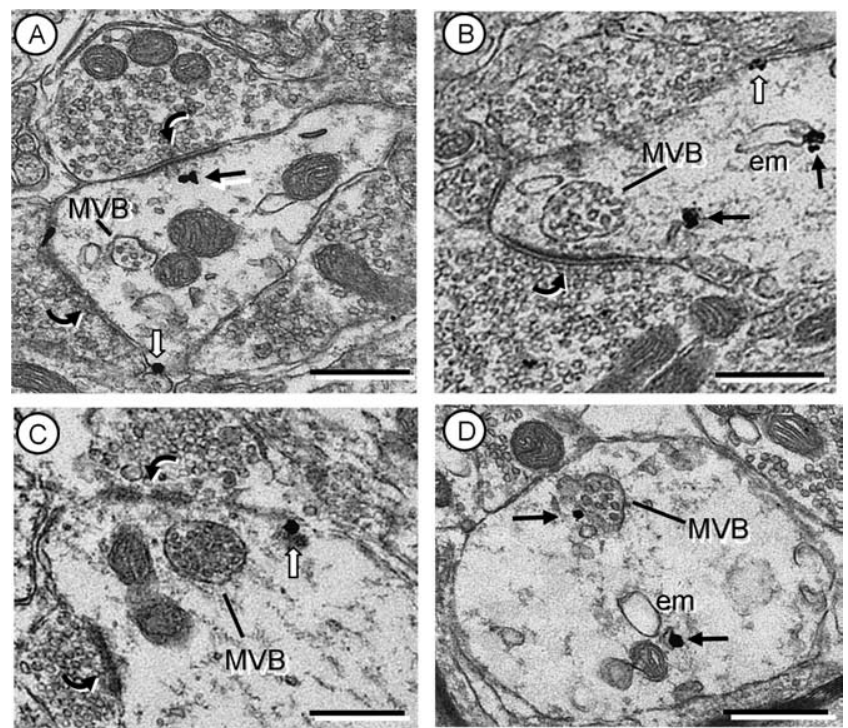

\section{(E) Acute Morphine}

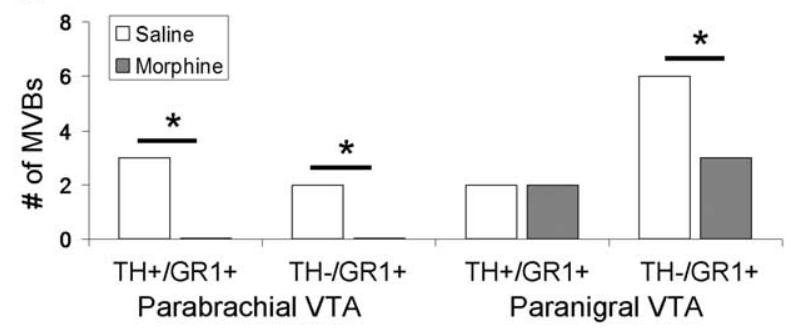

(F) Chronic Morphine

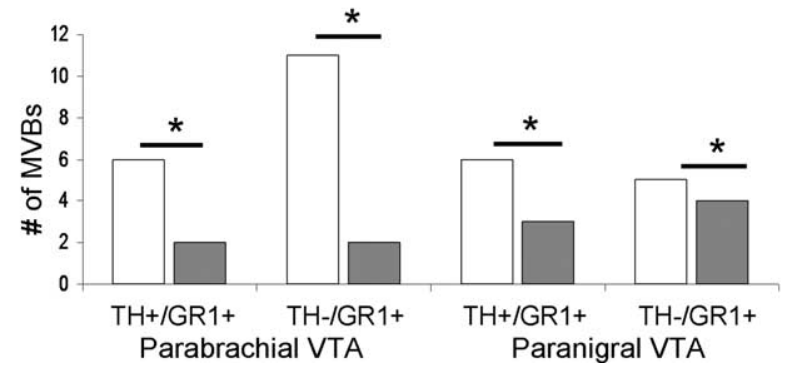

Figure 7. $\quad \boldsymbol{A}-\boldsymbol{D}$, Electron micrographs of MVBs in GluR1-labeled dendrites. MVBs are often seen in close proximity to excitatory-type synapses (curved arrows; $A-C$ ), and an MVB is in contact with a GluR1 immunogold particle (black arrow; $\boldsymbol{D})$. $\boldsymbol{E}$, After acute morphine administration, the number of MVBs decreased in both dopaminergic (TH+/GR1+) and nondopaminergic (TH-/GR1+) dendrites of the PB VTA and only in nondopaminergic (TH-/GR1+) dendrites of the PN VTA. After chronic morphine administration, there were significant decreases in the number of MVBs in both the PB and PN VTA, compared with saline controls. There is an inverse relationship between the number of MVBs and the amount of GluR1 synaptic labeling (Figs. 5, 6) in dendrites of the PB and PN VTA. White arrows, Plasmalemmal GluR1 labeling; em, endomembrane. ${ }^{*} p<0.05$. Scale bars, $500 \mathrm{~nm}$.

lected throughout each portion of the VTA to reduce the possibility of sampling bias. Control of these variables is shown by absence of significant variability between animals within each treatment group (see Materials and Methods).

It is important to note that although the VTA primarily contains dopaminergic (primary) and GABAergic (secondary) neurons, a tertiary group of nondopaminergic neurons has been reported with distinct pharmacological and physiological properties (Cameron et al., 1997). In addition, Yamaguchi et al. (2007) recently demonstrated the existence of glutamatergic neurons in the VTA. Thus, the GluR1-labeled dendrites that lack TH 

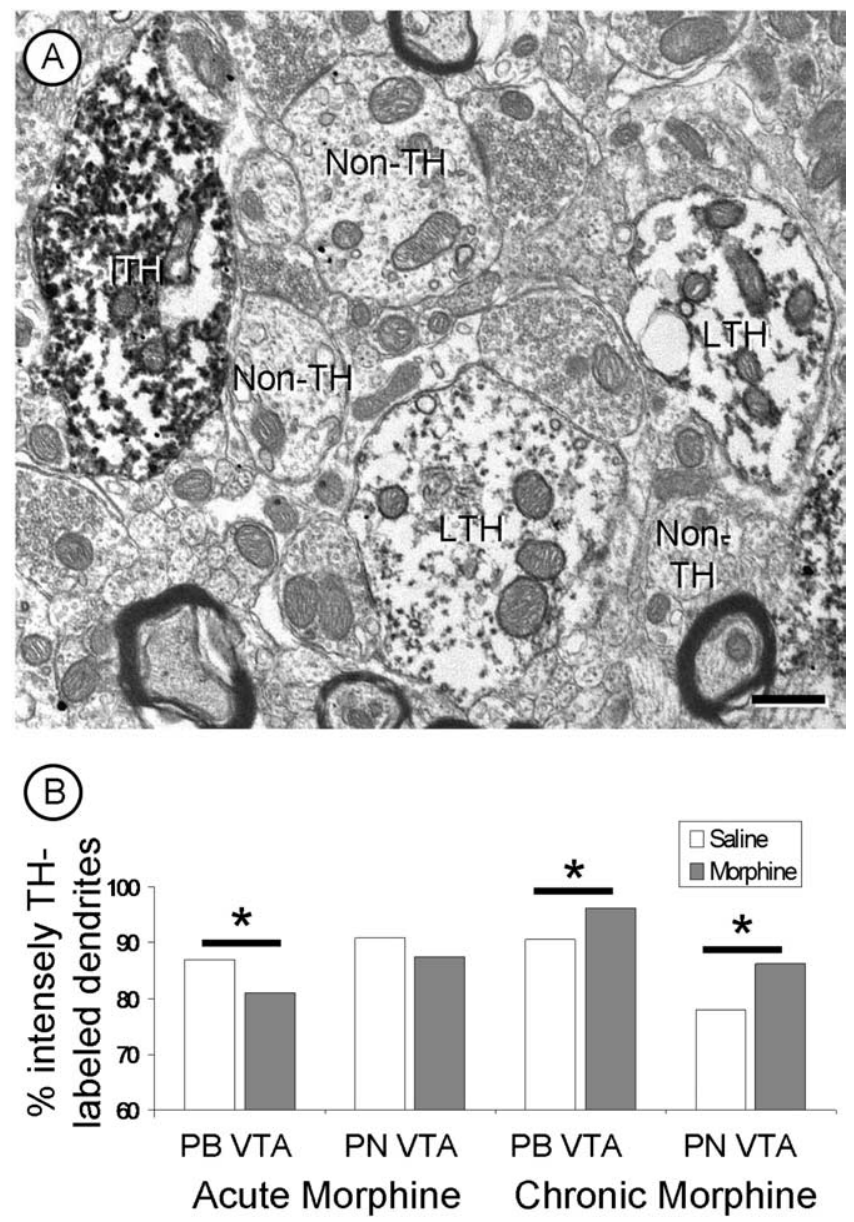

Figure 8. A, A representative electron micrograph showing dendrites with intense (ITH) or light (LTH) TH immunoreactivity in the PN VTA. Also present are several dendrites without TH peroxidase immunoreactivity (non-TH). $\boldsymbol{B}$, Acute morphine produces a significant decrease in the number of intensely TH-labeled dendrites of the PB VTA. Chronic intermittent escalating morphine results in a significant increase in the number of intensely TH-labeled dendrites in both the PB and PN VTA. ${ }^{*} p<0.05$. Scale bar, $500 \mathrm{~nm}$.

immunoreactivity may represent any of these secondary or tertiary cells. However, the majority of nondopaminergic neurons in the VTA have physiological properties of GABAergic neurons (Johnson and North, 1992; Steffensen et al., 1998).

\section{Effects of acute morphine administration on GluR1 distribution in the VTA}

After acute morphine administration, dopaminergic dendrites of the PB VTA show more plasmalemmal GluR1 distribution compared with the predominantly cytoplasmic distribution found in saline controls. These plasmalemmal GluR1 immunogold particles were in small, presumably more distal, dendrites. The increase in GluR1 in small dendrites may lead to enhanced postsynaptic glutamatergic activation, because excitatory glutamatergic inputs are more prevalent on distal portions of a dendrite (Peters et al., 1991). Consistent with this, more GluR1-labeled asymmetric (excitatory type) synapses were also seen in dopaminergic dendrites of the PB VTA after acute morphine administration. These findings suggests that a single dose of morphine results in increased plasmalemmal and synaptic mobilization of GluR1, an effect that would facilitate the bursting activity of mesocortical projecting dopaminergic neurons within the PB VTA.

In contrast, dopaminergic dendrites of the PN VTA showed no

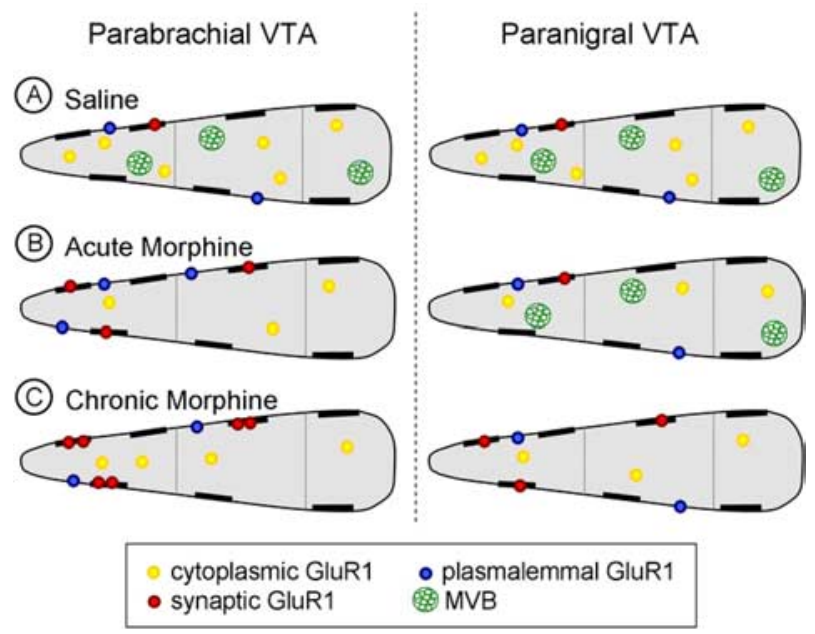

Figure 9. Schematic diagram of dendritic distribution of GluR1 immunogold particles in dopaminergic neurons of the PB and PN VTA after acute or chronic morphine administration. Each dendritic structure is divided by size (small, medium, and large; left to right, respectively) and dopaminergic dendrites of the PB VTA are represented on the left with dopaminergic dendrites of the PN VTA on the right side of the schematic. $A$, In saline controls, both the PB and PN VTA have similar, predominantly cytoplasmic (yellow circles) GluR1 gold particle distributions with sparse plasmalemmal (blue circles) GluR1 labeling. MVBs (green circles) are present in dendrites of both VTA regions. $\boldsymbol{B}$, In the PB VTA (left), acute morphine administration results in a decrease in cytoplasmic GluR1 gold labeling in small and medium-sized dendrites with an increase in plasmalemmal (in small dendrites only) and synaptic (red) GluR1 labeling. There is also a decrease in the number of MVBs seen in these dendrites. In the PN VTA, there is a decrease in cytoplasmic GluR1 labeling in small and medium-sized dendrites with a slight increase in plasmalemmal GluR1 labeling in small dendrites; however, there is no change in synaptic GluR1 labeling or prevalence of MVBs. C, After chronic morphine administration, increased synaptic GluR1 labeling ensues in the PB VTA (left) with an increased amount of GluR1 at each synapse (red) and a concurrent decrease in the number of MVBs present within these dendrites. Mesolimbic dopaminergic dendrites of the PN VTA (right) demonstrate an increase in the number of synapses labeled with GluR1 (red) and a decrease in the number of MVBs after chronic morphine administration, which did not occur with acute morphine administration. Together, these findings suggest that early activation of the mesocortical dopaminergic pathway of the PB VTA may result in a decrease in $\mathrm{mPFC}$ glutamate release, leading to subsequent changes in GluR1 localization in the mesolimbic dopaminergic pathway of the PN VTA.

significant changes in plasmalemmal or synaptic GluR1 labeling in animals receiving acute morphine compared with saline controls. There was, however, a significant acute morphine-induced increase in synaptic labeling of nondopaminergic dendrites of the PN VTA. Part of this difference may be explained by circuitry. Mesocorticalprojecting dopaminergic neurons receive direct PFC glutamatergic innervation, whereas there is an indirect effect of glutamate on mesolimbic-projecting dopaminergic neurons (Carr and Sesack, 2000) preferentially located in the PN VTA. This circuitry is implicated in AMPA-mediated tonic excitation of mesocorticalprojecting neurons, and inhibition of mesolimbic-projection neurons (Takahata and Moghaddam, 2000). In addition to the PFC inputs, however, the region-specific differences in AMPA GluR1 distributions in the VTA may also reflect morphine-induced changes in the activity of glutamate projections to the VTA from the lateral amygdala and other brain regions implicated in drug-seeking behavior (Geisler and Zham, 2005; Omelchenko and Sesack, 2007).

\section{Effects of chronic intermittent escalating morphine on GluR1 subcellular distribution}

Chronic intermittent-escalating morphine administration resulted in a significant increase in synaptic GluR1 labeling in dopaminergic and nondopaminergic dendrites of both VTA subregions. TH-immunoreactive dendrites of the PN VTA, which 
showed no significant changes in synaptic GluR1 labeling with acute morphine, showed an increase in the number of synapses labeled with GluR1 after intermittent-escalating morphine. Moreover, TH-immunoreactive dendrites of the PB VTA had significantly more synaptic GluR1 gold labeling at each synapse compared with saline controls. Thus, in addition to maintaining the increased number of labeled synapses in the PB VTA, as seen with acute morphine, chronic morphine also increases the number of AMPA GluR1 subunits at each synapse.

We found a significant negative relationship between the amount of synaptic GluR1 labeling and the presence of MVBs, late endosomal structures involved with degradation and, potentially, recycling of receptors (Katzmann et al., 2002; Stahl and Barbieri, 2002). AMPA receptors are highly mobile and continuously move in and out of postsynaptic densities (for review, see Song and Huganir, 2002). Recycling endosomes are thought to regulate this process by mediating the amount of AMPA receptors that are present at postsynaptic densities (Lüscher et al., 1999; Ehlers, 2000; Park et al., 2004). MVBs were strategically positioned near asymmetric (excitatory-type) synapses in dendrites without synaptic GluR1-gold labeling (Fig. 7A-C) or adjacent to cytoplasmic GluR1 gold particles (Fig. 7D). In contrast, MVBs were not present near synapses with GluR1 gold labeling (Figs. $5 B, D, 6$ ), suggesting that MVBs may play a role in AMPA receptor endocytosis.

We observed virtually no GluR1-labled MVBs despite previous work showing peroxidase labeling for GluR1 in these organelles (Baude et al., 1994). The lack of MVB GluR1 labeling may reflect a permeability issue for immunogold particles or the subunits may have undergone a conformational change or degradation during downregulation (Ehlers, 2000, 2004; Turrigiano, 2002), preventing immunocytochemical detection with the antiserum. Return of nondegraded GluR1 to functional synaptic sites may explain why there was little change in cytoplasmic and/or plasmalemmal distribution of GluR1 labeling, but large changes in the synaptic location of GluR1 in the VTA of rats receiving chronic morphine administration.

\section{Changes in TH immunoreactivity with morphine administration}

TH is highly regulated and has been shown to increase after chronic, but not acute, morphine administration (Beitner-Johnson and Nestler, 1991). We observed qualitative morphine-induced differences in the density of TH-peroxidase immunoreactivity in dendrites of the VTA. Such differences were observed previously (Bayer and Pickel, 1990) and reported to specifically relate to GABAergic inputs, which were more prevalent on the lightly labeled $\mathrm{TH}$ dendrites (Bayer and Pickel, 1991). Acute morphine produced a decrease in the ratio of intense to light TH-labeled cells in the $\mathrm{PB}$, but not $\mathrm{PN}$ VTA. In contrast, chronic morphine produced an increase in the ratio of intense to light $\mathrm{TH}$-labeled dendrites in both regions of the VTA supporting findings of increased $\mathrm{TH}$ synthesis after chronic morphine (Beitner-Johnson and Nestler, 1991). These changes provide some insight into potential region-specific differences in $\mathrm{TH}$ expression after morphine, but require quantitative measures to substantiate the subjective classifications of immunoreactivity intensity.

\section{Changes in dendritic size with morphine administration}

Chronic morphine administration has been shown to produce a significant decrease in neuronal size and length of neuronal processes in the VTA (Sklair-Tavron et al., 1996), although it has been questioned whether this is a function of morphine or alternatively, because of withdrawal from morphine (Spiga et al., 2003). Our findings support the idea of morphine-induced structural changes that are independent of opiate withdrawal (Fig. 3). Changes observed in the PN VTA support previous work and show a decrease in the average diameter of dopaminergic dendrites after chronic morphine administration. However, the opposite occurred in the PB VTA, where chronic morphine administration resulted in a significant increase in the average diameter of dopaminergic dendrites. Acute morphine administration also produced an increase in average diameter of dopaminergic dendrites in both VTA regions, which has not reported previously (Sklair-Tavron et al., 1996). The discrepancy in the findings may be attributable to differences in the methods of analysis or because of withdrawal effects from morphine. Previous work examined the VTA as a whole $24 \mathrm{~h}$ after the last morphine administration, which may have concealed some of the opposing regional size differences reported here.

\section{Implications}

Our results showing region-specific and duration-dependent differences in the subcellular distribution of GluR1 in the PB and PN VTA are consistent with the respective differential glutamatergic control of mesocortical and mesolimbic projection neurons (Bonci and Malenka, 1999; Takahata and Moghaddam, 2000). These differences are supported by the anatomical circuitry in each region (Van Bockstaele and Pickel, 1995; Sesack and Carr, 2002; Sesack et al., 2003), and demonstrate specific morphine-induced adaptations of motivational and reward systems of the brain.

Acute morphine administration increased the plasmalemmal density and number of GluR1-labeled synapses in dopaminergic dendrites of the PB VTA. In contrast, dopaminergic dendrites of the PN VTA, which generally do not receive direct PFC glutamatergic input, show changes in GluR1 labeling, specifically in postsynaptic densities, after chronic intermittent escalating morphine administration. The PFC, the primary target of mesocortical dopaminergic neurons predominantly found in the PB VTA, is involved with motivation and reinforcement (Schultz, 2002; Floresco and Magyar, 2006). The NAc, the primary target of mesolimbic dopaminergic neurons located mainly in the PN VTA, is associated with increased locomotor activity and rewarding effects of morphine (Koob and Bloom, 1988; Le Moal and Simon, 1991; Bals-Kubik et al., 1993). Together, these findings suggest that acute morphine administration may produce increased postsynaptic AMPA receptor-mediated glutamatergic transmission preferentially within cortical-projecting dopaminergic neurons which influence drug-seeking and -motivated behaviors. This activation pattern is distinct from that seen with chronic morphine administration in which glutamatergic synaptic plasticity preferentially occurs in dopaminergic neurons within the mostly mesolimbic projection system affecting, and potentially decreasing, the rewarding properties of morphine.

\section{References}

Adams MM, Fink SE, Shah RA, Janssen WG, Hayashi S, Milner TA, McEwen BS, Morrison JH (2002) Estrogen and aging affect the subcellular distribution of estrogen receptor-alpha in the hippocampus of female rats. J Neurosci 22:3608-3614.

Aicher SA, Sharma S, Mitchell JL (2002) Co-localization of AMPA receptor subunits in the nucleus of the solitary tract in the rat. Brain Res 958:454-458.

Bals-Kubik R, Ableitner A, Herz A, Shippenberg TS (1993) Neuroanatomical sites mediating the motivational effects of opioids as mapped by the 
conditioned place preference paradigm in rats. J Pharmacol Exp Ther 264:489-495.

Baude A, Molnár E, Latawiec D, McIlhinney RAJ, Somogyi P (1994) Synaptic and nonsynaptic localization of the GluR1 subunit of the AMPA-type excitatory amino acid receptor in the rat cerebellum. J Neurosci 14:28302843.

Bayer VE, Pickel VM (1990) Ultrastructural localization of tyrosine hydroxylase in the rat ventral tegmental area: relationship between immunolabeling density and neuronal associations. J Neurosci 10:2996-3013.

Bayer VE, Pickel VM (1991) GABA-labeled terminals form proportionally more synapses with dopaminergic neurons containing low densities of tyrosine hydroxylase-immunoreactivity in rat ventral tegmental area. Brain Res 559:44-55.

Beitner-Johnson D, Nestler EJ (1991) Morphine and cocaine exert common chronic actions on tyrosine hydroxylase in dopaminergic brain reward regions. J Neurochem 57:344-347.

Bonci A, Malenka RC (1999) Properties and plasticity of excitatory synapses on dopaminergic and GABAergic cells in the ventral tegmental area. J Neurosci 19:3723-3730.

Cameron DL, Wessendorf MW, Williams JT (1997) A subset of ventral tegmental neurons is inhibited by dopamine, 5-hydroxytryptamine and opioids. Neuroscience 77:155-166.

Carlezon WA Jr, Boundy VA, Haile CN, Lane SB, Kalb RG, Neve RL, Nestler EJ (1997) Sensitization to morphine induced by viral-mediated gene transfer. Science 277:812-814.

Carlin RK, Grab DJ, Cohen RS, Siekevitz P (1980) Isolation and characterization of postsynaptic densities from various brain regions: enrichment of different types of postsynaptic densities. J Cell Biol 86:831-845.

Carr DB, Sesack SR (2000) Projections from the rat prefrontal cortex to the ventral tegmental area: target specificity in the synaptic associations with mesoaccumbens and mesocortical neurons. J Neurosci 20:3864-3873.

Chan J, Aoki C, Pickel VM (1990) Optimization of differential immunogoldsilver and peroxidase labeling with maintenance of ultrastructure in brain sections before plastic embedding. J Neurosci Methods 33:113-127.

Eccles JC (1964) The physiology of synapses. Berlin: Springer.

Ehlers MD (2000) Reinsertion or degradation of AMPA receptors determined by activity-dependent endocytic sorting. Neuron 28:511-525.

Ehlers MD (2004) Deconstructing the axon: Wallerian degeneration and the ubiquitin-proteasome system. Trends Neurosci 27:3-6.

Floresco SB, Magyar O (2006) Mesocortical dopamine modulation of executive functions: beyond working memory. Psychopharmacology (Berl) 188:567-585.

Garzón M, Pickel VM (2001) Plasmalemmal mu-opioid receptor distribution mainly in nondopaminergic neurons in the rat ventral tegmental area. Synapse 41:311-328.

Geisler S, Zahm DS (2005) Afferents of the ventral tegmental area in the rat-anatomical substratum for integrative functions. J Comp Neurol 490:270-294.

Glass MJ, Kruzich PJ, Colago EE, Kreek MJ, Pickel VM (2005) Increased AMPA GluR1 receptor subunit labeling on the plasma membrane of dendrites in the basolateral amygdala of rats self-administering morphine. Synapse 58:1-12.

Guitart X, Beitner-Johnson D, Marby DW, Kosten TA, Nestler EJ (1992) Fisher and Lewis rat strains differ in basal levels of neurofilament proteins and their regulation by chronic morphine in the mesolimbic dopamine system. Synapse 12:242-253.

Johnson SW, North RA (1992) Two types of neurone in the rat ventral tegmental area and their synaptic inputs. J Physiol 450:455-468.

Kalivas PW, Bourdelais A, Abhold R, Abbott L (1989) Somatodendritic release of endogenous dopamine: in vivo dialysis in the A10 dopamine region. Neurosci Lett 100:215-220.

Karreman M, Moghaddam B (1996) The prefrontal cortex regulates the basal release of dopamine in the limbic striatum: an effect mediated by ventral tegmental area. J Neurochem 66:589-598.

Katzmann DJ, Odorizzi G, Emr SD (2002) Receptor downregulation and multivesicular-body sorting. Nat Rev Mol Cell Biol 3:893-905.

Koob GF, Bloom FE (1988) Cellular and molecular mechanisms of drug dependence. Science 242:715-723.

Kretschmer BD (1999) Modulation of the mesolimbic dopamine system by glutamate: role of NMDA receptors. J Neurochem 73:839-848.
Kruzich PJ, Chen AC, Unterwald EM, Kreek MJ (2003) Subject-regulated dosing alters morphine self-administration behavior and morphinestimulated [35S]GTPgammaS binding. Synapse 47:243-249.

Le Moal M, Simon H (1991) Mesocorticolimbic dopaminergic network: functional and regulatory roles. Am Physiological Society 71:155-234.

Leranth C, Pickel MV (1989) Electron microscopic pre-embedding double immunostaining methods. In: Tract tracing methods II: recent progress (Heimer L, Zabrosky L, eds). New York: Plenum.

Lessard A, Pickel VM (2005) Subcellular distribution and plasticity of neurokinin-1 receptors in the rat substantia nigra and ventral tegmental area. Neuroscience 135:1309-1323.

Liao D, Hessler NA, Malinow R (1995) Activation of postsynaptically silent synapses during pairing-induced LTP in CA1 region of hippocampal slice. Nature 375:400-404.

Lüscher C, Xia H, Beattie EC, Carroll RC, von Zastrow M, Malenka RC, Nicoll RA (1999) Role of AMPA receptor cycling in synaptic transmission and plasticity. Neuron 24:649-658.

Malinow R, Malenka RC (2002) AMPA receptor trafficking and synaptic plasticity. Annu Rev Neurosci 25:103-126.

Meltzer LT, Christoffersen CL, Serpa KA (1997) Modulation of dopamine neuronal activity by glutamate receptor subtypes. Neurosci Biobehav Rev 21:511-518.

Olson VG, Nestler EJ (2007) Topographical organization of GABAergic neurons within the ventral tegmental area of the rat. Synapse 61:87-95.

Olson VG, Zabetian CP, Bolanos CA, Edwards S, Barrot M, Eisch AJ, Hughes T, Self DW, Neve RL, Nestler EJ (2005) Regulation of drug reward by cAMP response element-binding protein: evidence for two functionally distinct subregions of the ventral tegmental area. J Neurosci 25:5553-5562.

Omelchenko N, Sesack SR (2007) Glutamate synaptic inputs to ventral tegmental area neurons in the rat derive primarily from subcortical sources. Neuroscience 146:1259-1274.

Park M, Penick EC, Edwards JG, Kauer JA, Ehlers MD (2004) Recycling endosomes supply AMPA receptors for LTP. Science 305:1972-1975.

Paxinos G, Watson C (1986) The rat brain in stereotaxic coordinates. Sydney: Academic.

Peters A, Palay SL, Webster HD (1991) The fine structure of the nervous system, Ed 3. New York: Oxford UP.

Pieribone VA, Aston-Jones G (1988) The iontophoretic application of Fluoro-Gold for the study of afferents to deep brain nuclei. Brain Res 475:259-271.

Reynolds ES (1963) The use of lead citrate at high $\mathrm{pH}$ as an electronopaque stain in electron microscopy. J Cell Biol 17:208-212.

Rollenhagen A, Lübke JH (2006) The morphology of excitatory central synapses: from structure to function. Cell Tissue Res 326:221-237.

Saal D, Dong Y, Bonci A, Malenka RC (2003) Drugs of abuse and stress trigger a common synaptic adaptation in dopamine neurons. Neuron 37:577-582.

Schmued LC, Fallon JH (1986) Fluoro-Gold: a new fluorescent retrograde axonal tracer with numerous unique properties. Brain Res 377:147-154.

Schultz W (2002) Getting formal with dopamine and reward. Neuron 36:241-263.

Sesack SR, Carr DB (2002) Selective prefrontal cortex inputs to dopamine cells: implications for schizophrenia. Physiol Behav 77:513-517.

Sesack SR, Carr DB, Omelchenko N, Pinto A (2003) Anatomical substrates for glutamate-dopamine interactions: evidence for specificity of connections and extrasynaptic actions. Ann N Y Acad Sci 1003:36-52.

Sesack SR, Pickel VM (1995) Ultrastructural relationship between terminals immunoreactive for enkephalin, GABA, or both transmitters in the rat ventral tegmental area. Brain Res 672:261-275.

Siegel SJ, Janssen WG, Tullai JW, Rogers SW, Moran T, Heinemann SF, Morrison JH (1995) Distribution of the excitatory amino acid receptor subunits GluR2(4) in monkey hippocampus and colocalization with subunits GluR5-7 and NMDAR1. J Neurosci 15:2707-2719.

Sklair-Tavron L, Shi WX, Lane SB, Harris HW, Bunney BS, Nestler EJ (1996) Chronic morphine induces visible changes in the morphology of mesolimbic dopamine neurons. Proc Natl Acad Sci U S A 93:11202-11207.

Song I, Huganir RL (2002) Regulation of AMPA receptors during synaptic plasticity. Trends Neurosci 25:578-588.

Spiga S, Serra GP, Puddu MC, Foddai M, Diana M (2003) Morphine 
withdrawal-induced abnormalities in the VTA: confocal laser scanning microscopy. Eur J Neurosci 17:605-612.

Stahl PD, Barbieri MA (2002) Multivesicular bodies and multivesicular endosomes: the "ins and outs" of endosomal traffic. Sci STKE 141: PE32.

Steffensen SC, Svingos AL, Pickel VM, Henriksen SJ (1998) Electrophysiological characterization of GABAergic neurons in the ventral tegmental area. J Neurosci 18:8003-8015.

Svingos AL, Garzón M, Colago EE, Pickel VM (2001) Mu-opioid receptors in the ventral tegmental area are targeted to presynaptically and directly modulate mesocortical projection neurons. Synapse 41:221-229.

Taber MT, Fibiger HC (1995) Electrical stimulation of the prefrontal cortex increases dopamine release in the nucleus accumbens of the rat: modulation by metabotropic glutamate receptors. J Neurosci 15:3896-3904.
Takahata R, Moghaddam B (2000) Target-specific glutamatergic regulation of dopamine neurons in the ventral tegmental area. J Neurochem $75: 1775-1778$.

Turrigiano GG (2002) A recipe for ridding synapses of the ubiquitous AMPA receptor. Trends Neurosci 25:597-598.

Van Bockstaele EJ, Pickel VM (1995) GABA-containing neurons in the ventral tegmental area project to the nucleus accumbens in rat brain. Brain Res 682:215-221.

Van Bockstaele EJ, Wright AM, Cestari DM, Pickel VM (1994) Immunolabeling of retrogradely transported Fluoro-Gold: sensitivity and application to ultrastructural analysis of transmitter-specific mesolimbic circuitry. J Neurosci Methods 55:65-78.

Wolf ME (2003) LTP may trigger addiction. Mol Interv 3:248-252.

Yamaguchi T, Sheen W, Morales M (2007) Glutamatergic neurons are present in the rat ventral tegmental area. Eur J Neurosci 25:106-118. 